Japan. J. Trop. Med., Vol. 10, 223-234, 1969

\title{
JAPANESE ENCEPHALITIS PURIFIED VACCINE ULTRACENTRIFUGE-PURIFIED VACCINE FROM INFECTED MOUSE BRAINS
}

\author{
KEISUKE TAKAKU, TAKAYOSHI YAMASHITA, TAKEICHI OSANAI, \\ Iwao YOSHIDA, MASAHIKo KATO, Hideo GODA, \\ Mitsuo TAKAGI AND TSUTOMU HIROTA \\ Kan-onji Institute, The Research Foundation for Microbial Diseases of \\ Osaka University, Kan-onji, Kagawa, Japan
}

TSUNEHISA AMANO, Konosuke FUKAI, NobUhaRU KUNITA, Kozo INOUE, Ko SHOJI, AKIRA IGARASHI AND TONETARO ITO

The Research Institute for Microbial Diseases, Osaka University, Yamada-kami, Suita, Osaka, Japan

Japanese encephalitis is one of the most important infectious diseases in East Asia including Japan, Korea, Siberia, China and Taiwan, where various efforts have been made for the eradication of this horrible disease. In the middle of 1950's, formalin-inactivated supernatant of brain homogenate from mice infected with Japanese encephalitis virus was put into practice in Japan. Since then extensive efforts have been made to prepare more potent vaccine and to eliminate possible contaminating substances causing allergic encephalomyelitis.

In 1965 two kinds of purified vaccine prepared from infected mouse brains were introduced. One was devised by investigators at the Nippon Institute for Biological Science and was prepared by protamine treatment of ethanol precipitated viruses. The other was developed in this institute and was prepared by ultracentrifugation of the protamine- and active carbon-treated viruses ${ }^{1}$. After extensive examination and field surveys by the Comittee on the Japanese Encephalitis Vaccine, which has been organized by experts throughout Japan, these vaccines have been recognized as being better than the previous vaccine, and have been used in practice.

\section{Method of preparation of the vaccine}

As shown in Fig. 1, two alternative methods can be used for vaccine purification, i. e., purification of inactivated virus and inactivation of purified live viruses. Both methods give comparative purities and potencies.

Four week old albino mice of mixed breed and both sexes are inoculated intracerebrally with Japanese encephalitis virus, Nakayama-Yoken strain ${ }^{2}$. After full development of the disease, moribund mice are killed, and their brains are taken out and homogenized in phosphate buffered saline, $\mathrm{pH}$ 8.0. After low speed centrifugation, the supernatant is treated with protamine sulfate in an ice bath as shown in the figure. Then, the protamine precipitate is removed by centrifugation. 
Fig. 1. Purification of Japanese Encephalitis Vaccine

(Biken Method)

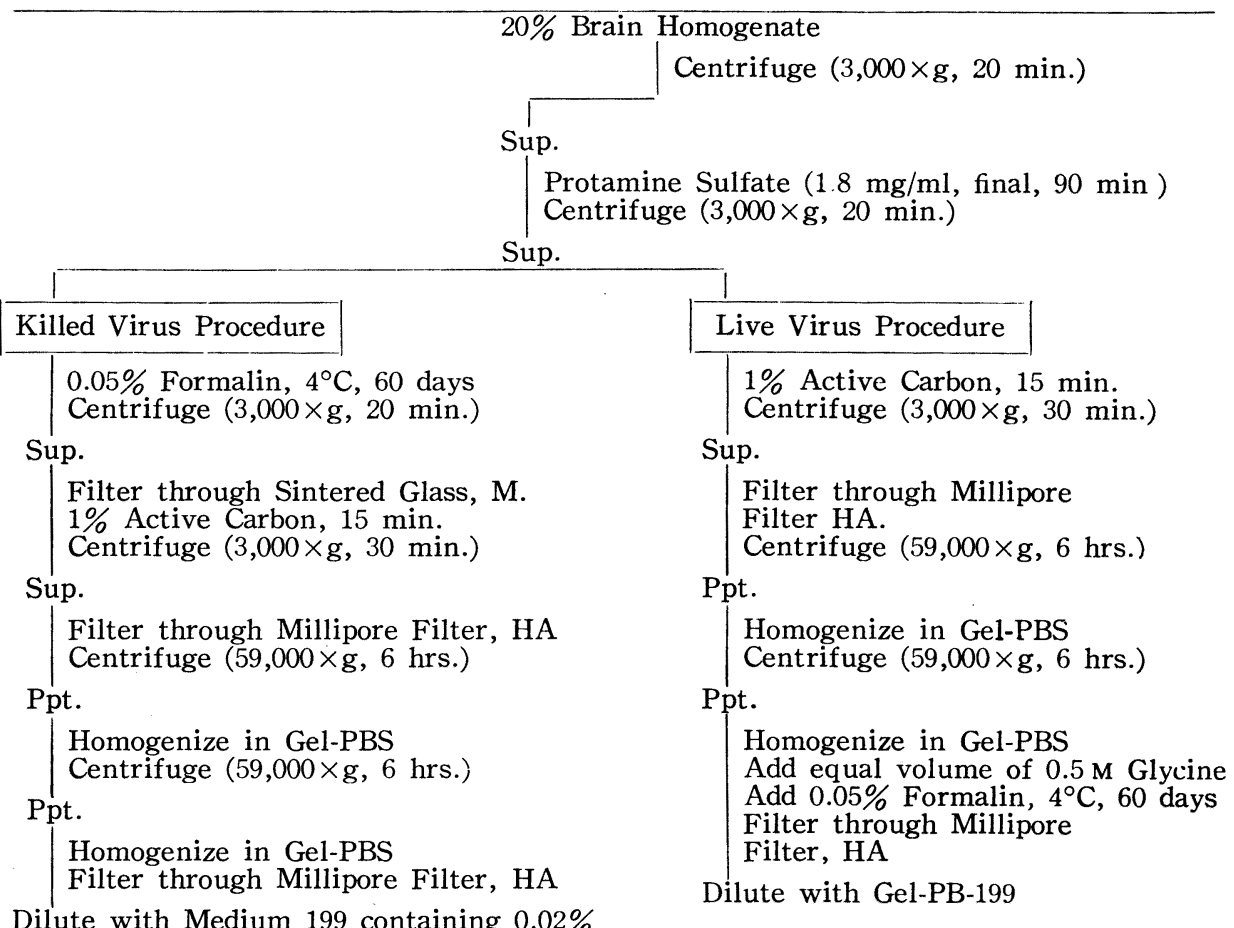

Dilute with Medium 199 containing $0.02 \%$

Gelatine and $\mathrm{M} / 150$ Phosphate Buffer, $\mathrm{pH} 7.2$

(Ge1-PB-199)

In the "live virus procedure" the protamine extract is further treated with active carbon in an ice bath to adsorb some non-viral substance. The carbon is removed by centrifugation. For higher purification the supernatant should be filtrated through a Millipore filter, type HA. The clarified virus suspension is centrifuged at $59,000 \times \mathrm{g}$ for 6 hours in a preparative ultracentrifuge, Model $40 \mathrm{P}$, 55PA or 55P-2 fitted with an RP-21 rotor, from Hitachi Ltd. Then the supernatant is slowly removed until $1 / 20$ volume of the bottom layer of supernatant is left. The pellet and the bottom $1 / 20$ portion of supernatant are collected and homogenized in $0.02 \%$ gelatine in phosphate buffered saline, $\mathrm{pH} \mathrm{7.2,} \mathrm{(Gel-PBS)} \mathrm{in}$ a Virtis 45 homogenizer. The resulting virus suspension is again ultracentrifuged in the same condition. The pellet and the bottom $1 / 20$ portion of supernatant are homogenized. The suspended viruses are inactivated with formalin and glycine at $4^{\circ} \mathrm{C}$. Glycine is necessary for maintaining a high immunogenic potency during the inactivation period. During this period the inactivation is checked at intervals by intracerebral injection of the suspension into suckling mice. Usually inactivation is complete within 45 days, but continued further 2 to 3 weeks longer.

After filtration through a Millipore filter membrane, type HA, the virus suspension is diluted to the desired concentration with TC Medium 199 (Difco) con taining $0.02 \%$ gelatine and M/150 phosphate buffer, $\mathrm{pH} 7.2$ (Gel-PB-199). 
In the "killed virus procedure" the viruses are inactivated following the protamine treatment. In this case the addition of glycine is unnecessary. Before active carbon treatment the inactivated virus suspension is passed through a sintered glass filter, grade $M$, to remove flocculent precipitate which has been formed during the inactivation period. The virus particles are purified by two cycles of ultracentrifugation under the same condition used in the live virus procedure. For routine production the killed virus procedure is employed. The final vaccine preparation contains 2 to $5 \mu \mathrm{g}$ of hot trichloracetic acid (TCA)-precipitable (proteinous) nitrogen per $\mathrm{ml}$.

In practical measures, about $800 \mathrm{ml}$ of the material can be processed at one time in a Hitachi ultracentrifuge, fitted with an RP-21 rotor. If the centrifuge is run 3 times a day, about 12 liters of the virus material can be handled in 5 working days per week. Therefore, if 10 ultracentrifuges are available, 120 liters of the virus material, corresponding roughly to 60,000 to 70,000 mice, can be routinely managed a week.

\section{Purity of the vaccine}

Table 1 shows the results obtained by the live virus procedure using a single cycle of ultracentrifugation. As shown in this table, the active carbon step yield material for ultracentrifugation which was about twice as pure as the original protamine extract.

Table 1. Virus Titers and Protein Contents following each Purification Step*

\begin{tabular}{|c|c|c|c|c|c|c|}
\hline \multirow{2}{*}{ Treatment } & & \multicolumn{3}{|c|}{$\begin{array}{c}\text { With active, carbon } \\
\text { treatment }\end{array}$} & \multicolumn{2}{|c|}{$\begin{array}{c}\text { Without active carbon } \\
\text { treatment }\end{array}$} \\
\hline & & $1 / 20$ & $\begin{array}{l}\text { Bottom } \\
\text { sup.+Pellet }\end{array}$ & Pellet only & $\begin{array}{c}\text { Bottom } \\
1 / 20 \text { sup. }+ \text { Pellet }\end{array}$ & Pellet only \\
\hline \multirow{3}{*}{$\begin{array}{l}\text { Protamine } \\
\text { treatment }\end{array}$} & $\mathrm{PFU} / \mathrm{ml}$ & & $11.1 \times 10^{8}$ & $17.9 \times 10^{8}$ & $7.8 \times 10^{8}$ & $12.5 \times 10^{8}$ \\
\hline & $\mu \mathrm{g}$ protein $/ \mathrm{ml}$ & & 3.397 & 3,599 & 3,393 & 3,223 \\
\hline & $\mathrm{PFU} / \mu \mathrm{g}$ protein & & 33 & 60 & 28 & 38 \\
\hline \multirow{3}{*}{$\begin{array}{l}\text { Active } \\
\text { carbon } \\
\text { treatment }\end{array}$} & $\mathrm{PFU} / \mathrm{ml}$ & & 11. $3 \times 10^{8}$ & $16.7 \times 10^{8}$ & & \\
\hline & $\mu \mathrm{g}$ protein $/ \mathrm{ml}$ & & 1,283 & 1,427 & & \\
\hline & $\mathrm{PFU} / \mu \mathrm{g}$ protein & & 87 & 119 & & \\
\hline \multirow{4}{*}{$\begin{array}{l}\text { Single } \\
\text { ultracentri- } \\
\text { fugation }\end{array}$} & $\mathrm{PFU} / \mathrm{ml}$ & & $51.8 \times 10^{8}$ & $77.7 \times 10^{8}$ & $102.5 \times 10^{8}$ & $77.5 \times 10^{8}$ \\
\hline & $\mu \mathrm{g}$ protein/ml & & 730 & 105 & 2,053 & 160 \\
\hline & $\mathrm{PFU} / \mu \mathrm{g}$ protein & & 1,960 & 6,686 & 437 & 6,829 \\
\hline & $\begin{array}{l}\text { Per cent } \mathrm{PFU} \\
\text { recovery }\end{array}$ & & 79 & 34 & 95 & 67 \\
\hline
\end{tabular}

* Average values of several experiments.

When only the pellet obtained by ultracentrifugation is used for vaccine, the purification ratio will be greatly increased but the loss of viruses be also significant. To avoid loss of virus and increase purity, two cycles of ultracentrifugation and harvesting the pellet and the bottom $1 / 20$ portion of the supernatant obtained at each cycle has been adopted as the standard method. 
Fig. 2. Immunodiffusion Analysis of Samples from Various Purification Steps

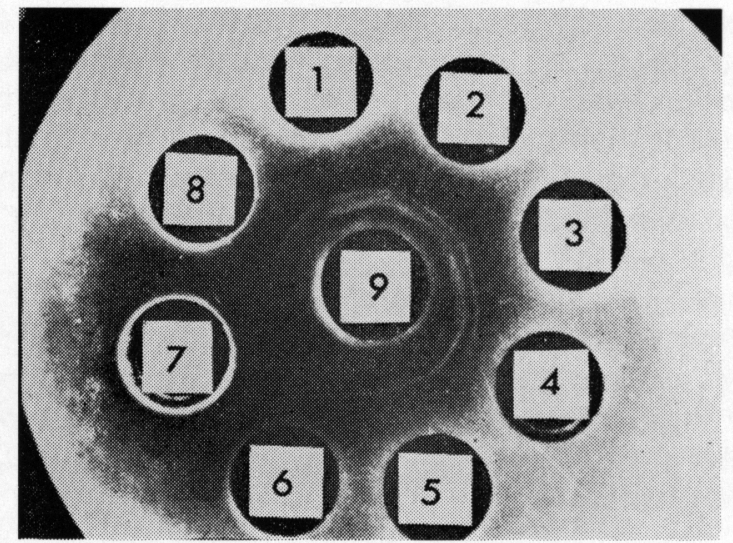

1: Protamine extract.

2: Active carbon-treated protamine extract.

3: Supernatant from the first ultracentrifugation.

4: Pellet and bottom $1 / 20$ of the supernatant from the first ultracentrifugation.

5: Supernatant from the second ultracentrifugation.

6: Pellet and bottom $1 / 20$ of the supernatant from the second ultracentrifugation.

7: Normal mouse serum.

8: Supernatant from normal mouse brain homogenate.

9: Anti-normal mouse brain rabbit serum (RMB-2).

Fig. 2 shows an Ouchterlony plate of diffusion of samples at various purification steps against rabbit anti-normal mouse brain serum. All the antigens, 1 through 6 , were of stages of purification of a single particular batch of protamine extract, and their concentrations were adjusted to 6.5 times that of the final vaccine product by ultrafiltration or dilution. As shown in this figure, some antigens in the mouse brain homoginate and the samples of the earlier purification steps cross-reacted with mouse serum proteins. As the purification proceeded, the antigens, which reacted with anti-normal mouse brain serum, were lost. The final product in well No. 6 contained little of these antigens.

Fig. 3 shows an electron micrograph of the final vaccine seen by the negative staining method $^{3)}$. Many typical virus particles of $40 \mathrm{~m} \mu$ diameter and little contaminating materials can be seen.

\section{Immunogenic potencies of the vaccine}

Fig. 4 shows the distribution of the potencies of our products for 1966 and 1967, expressed as the $\log _{4}$ of the mouse $\mathrm{ED}_{50}$ 's plotted against the $\log _{10}$ of the challenge virus doses in $\mathrm{LD}_{50} .{ }^{1{ }^{14)}}$ The open circles represent our products, and the solid circles are for the standard vaccines of each year from the National Institute of Health of Japan. The solid lines represent the proposed standard distribution lines for the standard vaccines.

As shown in this figure, most of the plots for our ultracentrifure-purified vaccine preparations are far above the proposed line. 
Fig. 3. Electron Microzraph of Ultracentrifuge-Purified Vaccine (Negatively Stained by Phosphotungstate)

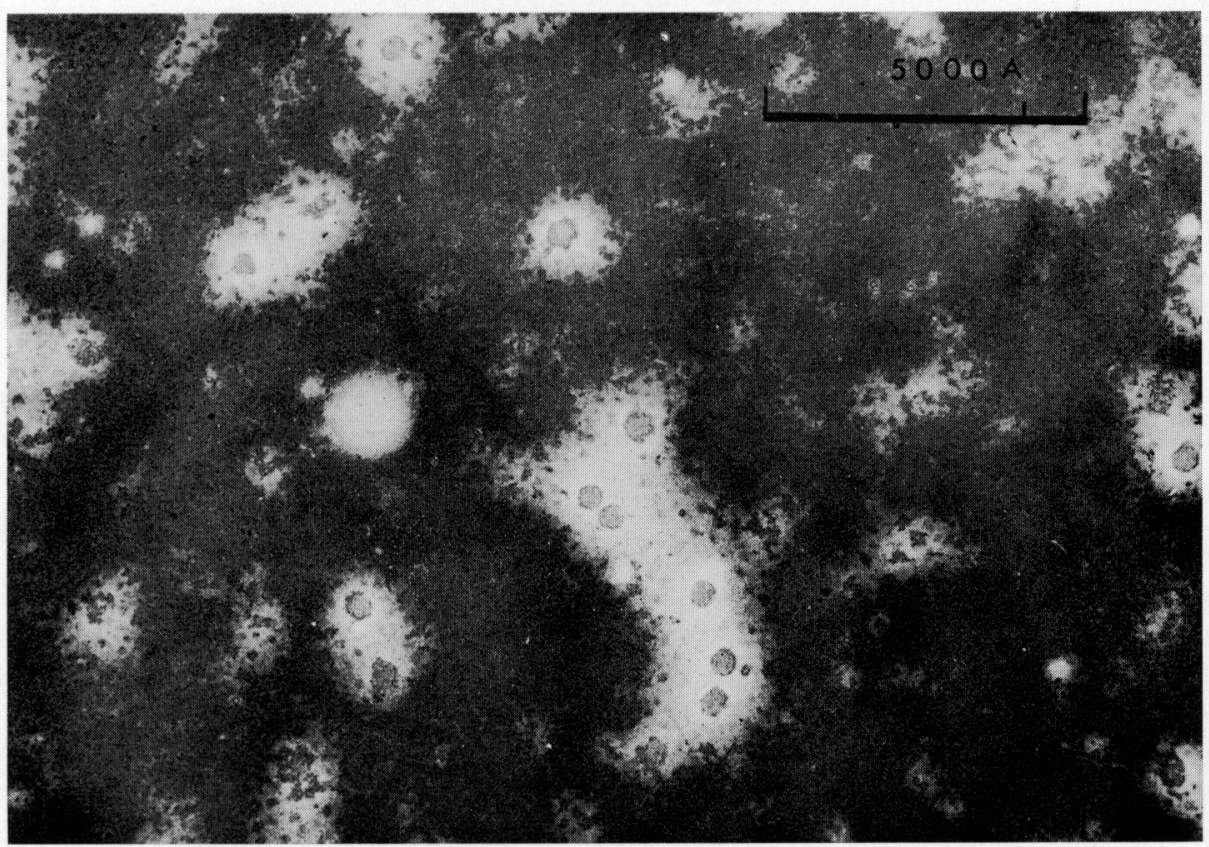

Fig. 4. Mouse $\mathrm{ED}_{50}$ of Ultracentrifuge-Purified JE Vaccine Prepared for 1966 and 1967

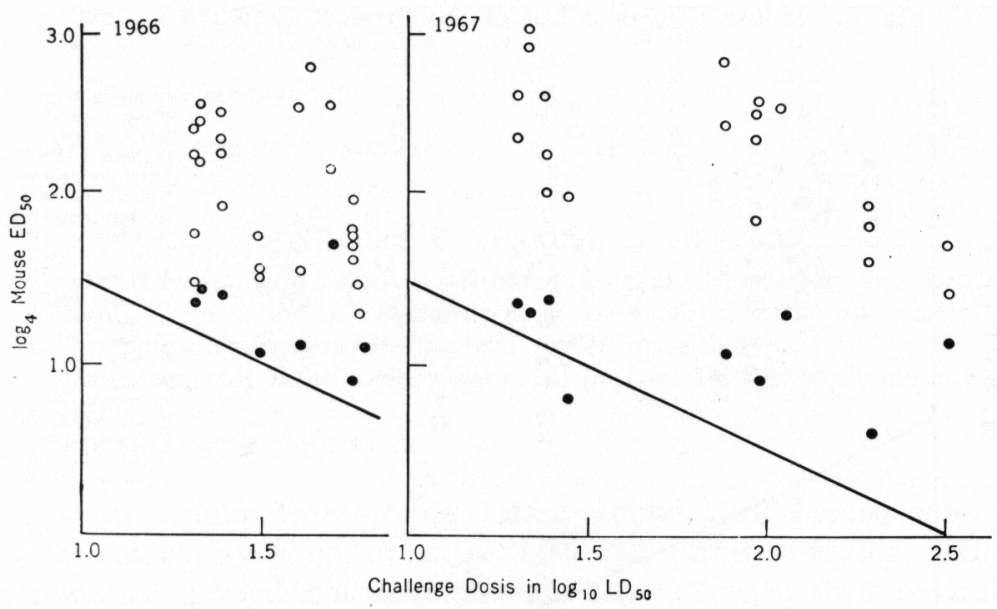

$\bigcirc$ : Ultracentrifuge-purified vaccine,

- Standard reference vaccine from National Institute of Health of Japan. 
Table 2. Effect of the Suspending Medium on the Stability of Ultracentrifuge-Purified Vaccine Stored at $2^{\circ}$ to $5^{\circ} \mathrm{C}$

\begin{tabular}{lrrrrr}
\hline & \multicolumn{5}{c}{$\begin{array}{c}\text { Potency at the end of indicated } \\
\text { month after preparation* }\end{array}$} \\
\cline { 2 - 6 } & 0 & 2 & 4 & 6 & 12 \\
\hline $\begin{array}{l}\text { Suspending medium } \\
\text { M } 75 \text { phosphate buffered saline }\end{array}$ & 1.9 & 1.6 & $<1.0$ & $<1.0$ & $<1.0$ \\
$0.02 \%$ Gelatine in M/75 phosohate buffered saline & 1.9 & 2.1 & 2.6 & 2.1 & 1.6 \\
$\begin{array}{l}\text { 0.02\% Gelatine and M/150 phosphate buffer in TC } \\
\text { Medium 199 }\end{array}$ & 1.9 & 2.3 & 2.8 & 2.6 & 2.5 \\
Reference protamine vaccine** & 1.9 & 1.9 & 2.0 & 2.0 & 2.1 \\
\hline Challenge virus doses in mouse $\mathrm{LD}_{50}$ & 26 & 24 & 16 & 20 & 14 \\
\hline
\end{tabular}

This test lot of vaccine contained $2.1 \mu \mathrm{g}$ hot TCA-precipitable nitrogen per $\mathrm{ml}$.

* Expressed as the $\log _{4}$ of the mouse $\mathrm{ED}_{50}$.

** Standard vaccine from the National Institute of Health of Japan distributed for 1965 production season.

\section{Stability of the vaccine}

As shown in Table 2, the ultracentrifuge-purified vaccine is unstable and loses its immunogenic potency within a few months when it is suspended in phosphatebuffered saline, $\mathrm{pH} 7.2$, which has been used as suspending medium for old protamine vaccine, and stored at $4{ }^{\circ} \mathrm{C}$. Many chemicals were tested for their ability to maintain the potency of purified vaccine. TC medium 199 (Difco) fortified with $0.02 \%$ gelatine and M/150 phosphate buffer (Gel-PB-199) was finally found to give the best results, as shown in this table, and adopted as the suspending medium for the purified vaccine.

Fig. 5. Mouse $\mathrm{ED}_{50}$ of a Lot of the Product Prepared in 1966

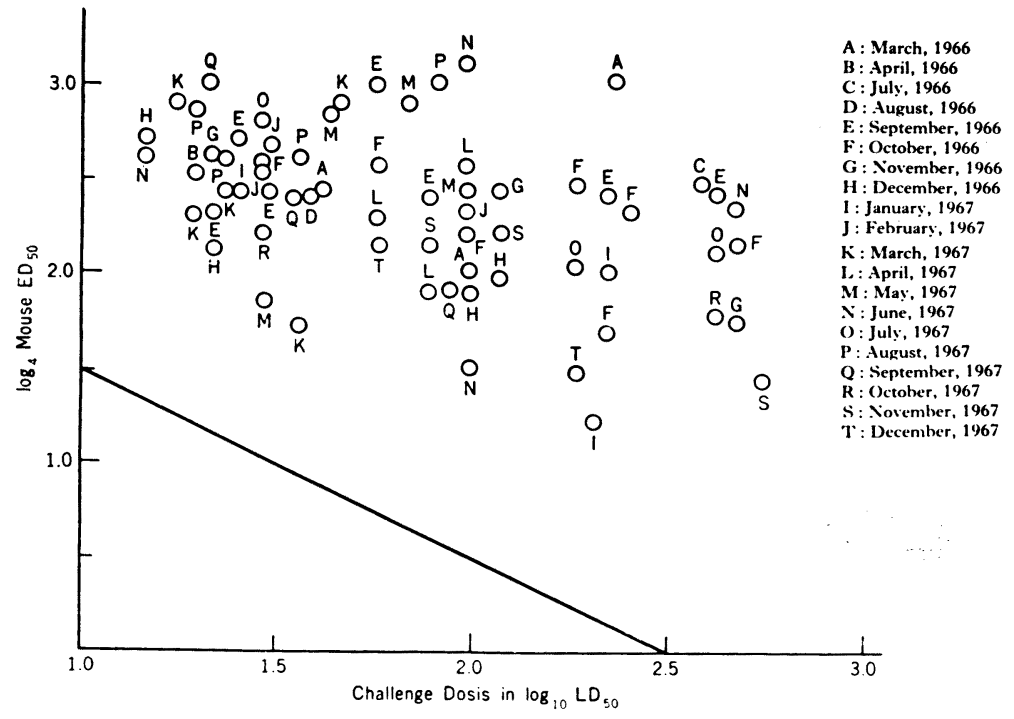


One of our products, manufactured during the 1966 production season, was examined at intervals on its immunogenic potency. This lot of vaccine contained $2.5 \mu \mathrm{g}$ of hot TCA-precipitable nitrogen per ml. As shown in Fig. 5, the potency of this vaccine has been well maintained at $4^{\circ} \mathrm{C}$ over a period of more than 20 months.

\section{Elimination of encephalitogenic substances from the vaccine}

When vaccine is prepared from brain tissue, there is a danger that it may be contaminated with substances which could cause allergic encephalomyelitis in persons immunized with it. Since administration of Japanese encephalitis vaccine started in the middle of 1950's, no compatible case of allergic encephalomyelitis resulting from the administration of the vaccine has been reported, even before ultracentrifuge-purified vaccine was introduced. This problem of possible contamination by encephalitogenic substances is still very important, however, when it is considered that the number of vaccinated people has recently been increasing rapidly.

Both the ultracentrifuge-purified vaccine and the old protamine vaccine were concentrated 50 times by lyophilization. The concentrated vaccines were injected with Freund's complete adjuvant intramuscularly into cynomolgus monkeys. As shown in Table 3, no monkey, receiving either kind of concentrated vaccine, showed clinical paralysis. When animals were examined on the 35 th day after injection, no histopathological lesion was found in their central nervous system.

Table 3. Occurrence of Allergic Encephalomyelitis in Cynomolgus Monkeys after Single Injection of Various Antigens

\begin{tabular}{|c|c|c|c|c|c|}
\hline \multirow{2}{*}{ Antigen } & \multirow{2}{*}{$\mathrm{mg} \mathrm{N} / \mathrm{ml}^{*}$} & \multirow{2}{*}{ Dose, $\mathrm{ml}$} & \multirow{2}{*}{$\begin{array}{l}\text { Clinical } \\
\text { paralysis }\end{array}$} & \multicolumn{2}{|c|}{$\begin{array}{l}\text { Histological } \\
\text { lesion }\end{array}$} \\
\hline & & & & Brain & $\begin{array}{l}\text { Spinal } \\
\text { cord }\end{array}$ \\
\hline Normal rabbit spinal cord homogenate & 1.0 & 1.0 & $4 / 4$ & $4 / 4$ & $2 / 4$ \\
\hline Normal mouse brain homogenate & $\begin{array}{c}10.0 \\
0.98\end{array}$ & $\begin{array}{l}1.0 \\
1.0\end{array}$ & $\begin{array}{l}0 / 4 \\
0 / 4\end{array}$ & $\begin{array}{l}1 / 4 \\
0 / 4\end{array}$ & $\begin{array}{l}2 / 4 \\
0 / 4\end{array}$ \\
\hline $50 \times$ concentrated $^{* *}$ protamine vaccine & 5.9 & 1.0 & $0 / 4$ & $0 / 4$ & $0 / 4$ \\
\hline $\begin{array}{l}50 \times \text { concentrated } * * \text { ultracentrifuge- } \\
\text { purified vaccine }\end{array}$ & 0.12 & 1.0 & $0 / 12$ & $0 / 12$ & $0 / 12$ \\
\hline
\end{tabular}

Antigen was mixed with an equal volume of adjuvant containing $85 \%$ Drackeol, $15 \%$ Arlacel A and $2 \mathrm{mg} / \mathrm{ml}$ Mycobacterium tuberculosis, strain Aoyama B, and injected intramuscularly into the femoral region on either side.

* Total nitrogen (for brain and spinal cord) or hot TCA-precipitable nitrogen (for vaccines).

** Concentrated by lyophilization.

All the control animals receiving rabbit spinal cord homogenate, however, developed clinical paralysis on or after 14th day after injection. Histopathological examination showed that these animals had lesions in their central nervous system. No monkey showed clinical paralysis after injection of mouse brain homogenate. However, some of them showed lesions in the brain and spinal cord.

Recently, a basic protein extracted from the tissues of the central nervous 
system of various animals at an acidic $\mathrm{pH}$ has been shown to produce allergic encephalomyelitis in experimental animals ${ }^{5) 6}$. This antigen prepared from normal mouse brain can develope a definite precipition line against anti-normal mouse brain antiserum, but not against anti-ultracentrifuge-purified vaccine antiserum, as shown in Fig. 6. On the other hand, concentrated ultracentrifuge-purified

Fig. 6. Immunodiffusion Analysis of Ultracentrifuge-Purified JE Vaccine.

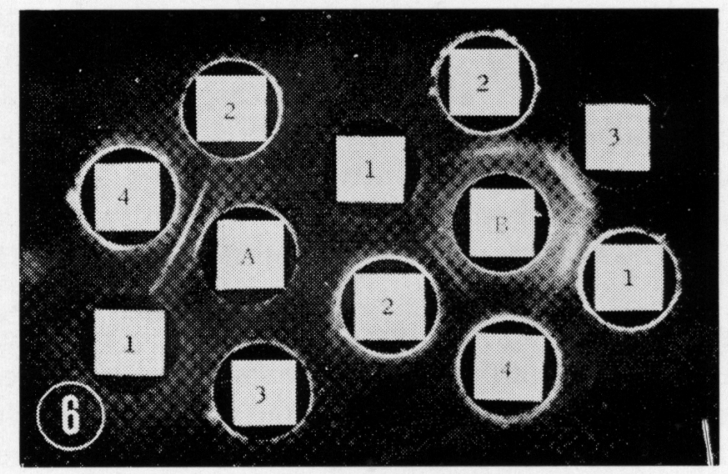

A: Anti-ultracentrifuge-purified vaccine rabbit serum (RUV-9).

B : Anti-normal mousebrain rabbit serum (RMB-24).

1: Ultracentrifuge-purified vaccine (15 times concentration of the final vaccine product).

2: Supernatant from 30 per cent normal brain homogenate.

3 : Encephalitogenic basic protein from mouse brain $(24 \mu \mathrm{g} \mathrm{N} / \mathrm{ml})$.

4 : Normal mouse serum.

vaccine occasionally developes a few faint lines against anti-normal mouse brain antiserum. However, neither fusion nor spur-formation is observed between the precipition lines formed by the vaccine and that by the encephalitogenic basic protein, and only the clear intersection between them can be observed. These results indicate the absence of encephalitogenic basic protein in the ultracentrifuge-purified vaccine.

\section{Side effects observed in people inoculated with the vaccine}

The old protamine vaccine used previously usually gave severe local pain when injected. The ultracentrifuge-purified vaccine, however, gives little or no pain among the people inoculated. Table 4 shows the side effects observed in a group of subjects following the administration of the ultracentrifuge-purified vaccine. As shown in this table, this vaccine is one of the most favorable vaccines in practical use.

\section{Antibody response among the people inoculated with the vaccine}

As a preliminary field trial, ultracentrifuge-purified vaccine was administrated among the volunteers through kind cooperation of Departments of Pediatrics of both Osaka Medical College and The Keio University Hospital. As shown in Fig. 7, the serum neutralizing antibody levels showed definite increase after the inoculation of this vaccine ${ }^{17)}$. 
Table 4. Side Effects Observed Following Administration of Ultracentrifuge-Purified JE Vaccine*

\begin{tabular}{lcc} 
& Numer observed** & Per cent incidence \\
\hline Local pain & 3 & 0.4 \\
Local pain on pressure & 36 & 5.2 \\
Local rash & 21 & 3.1 \\
Local swelling & 0 & 0 \\
Slight fever (less than $1^{\circ} \mathrm{C}$ rise) & 3 & 0.4 \\
High fever (more than $1^{\circ} \mathrm{C}$ rise) & 0 & 0 \\
\hline
\end{tabular}

* Administration: subcutaneous injection of $1.0 \mathrm{ml}$ dose into upper arm on one side.

** Total number observed: 675 persons.

Fig. 7

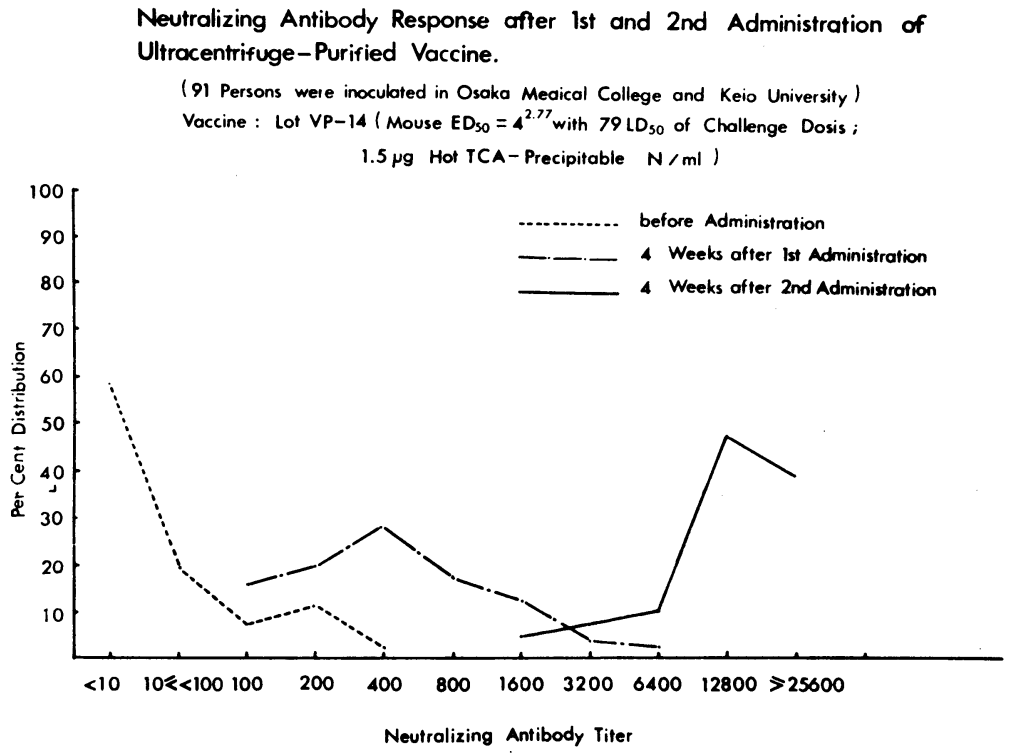

8. Ultracentrifuge-purifled vaccine prepared from a current strain, JaGAr $\# 01$

For a long time antigenic composition of Japanese encephalitis virus was regarded to be homogeneous among the various strains. As more strains were isolated from mosquitoes and from patients, however, their antigenic heterogeneity was revealed. Most of currently isolated strains were shown to possess similar antigenic composition, but they were different, to some extent, from NakayamaYoken strain, which is used for present vaccine, in the antigenic composition ${ }^{8) 9}$ ) 10).

In spite of the efforts of many investigators, the currently isolated strains of Japanese encephalitis virus have not given any good vaccine when prepared by a similar method to the present Nakayama vaccine.

In this respect it was thought that the failures might be due to inadequate 
methods for preparing vaccine. Ultracentrifuge-purified vaccine was prepared by similar method to our Nakayama vaccine from adult mouse brains infected with JaGAr $\# 01$ strain, which was isolated from mosquito, Culex tritaeniorhynchus in $1959^{11}$.

As shown in Table 5 , this JaGAr $\# 01$ vaccine could protect immunized mice against challenge by the homologous strain, while it showed lower potency against challenge by the hetrologous Nakayama strain. On the other hand, the Nakayama vaccine gave the same degrees of protection against challenge by either strain. When the potencies of vaccines were examined by neutralizing antibody test by plaque reduction ${ }^{7)}$, both the vaccine gave good antibody responses in immunized mice as shown in Table 6.

Table 5. Comparison of Potencies of Ultracentrifuge-Purified Vaccines Prepared from the JaGAr $¥ 01$ and Nakayama Strains by the Direct Mouse Challenge Test

\begin{tabular}{|c|c|c|c|c|c|c|c|c|c|}
\hline \multirow{4}{*}{ Vaccine } & \multicolumn{9}{|c|}{ Challenge virus } \\
\hline & \multirow{2}{*}{\multicolumn{5}{|c|}{$\frac{\text { JaGAr } \$ 01\left(13 \text { mouse } L^{2} D_{50}\right)}{\text { Vaccine dilution }}$}} & \multicolumn{4}{|c|}{ Nakayama (51 mouse $L D_{50}$ ) } \\
\hline & & & & & & \multicolumn{4}{|c|}{ Vaccine dilution } \\
\hline & $4^{0}$ & $4^{1}$ & $4^{2}$ & $4^{3}$ & $\mathrm{ED}_{50}$ & $4^{0}$ & $4^{1}$ & $4^{2}$ & $4^{3} \quad \mathrm{ED}_{50}$ \\
\hline JaGAr $¥ 01$ vaccine** & $0 / 10^{*}$ & $2 / 10$ & $2 / 10$ & $2 / 9$ & $4^{3.0}$ & $5 / 9$ & $7 / 9$ & $8 / 10$ & $7 / 9 \quad 4^{0.5}$ \\
\hline Nakayama vaccine ${ }^{* * *}$ & $0 / 7$ & $2 / 8$ & $2 / 10$ & $2 / 10$ & $4^{2.3}$ & $0 / 10$ & $0 / 9$ & $4 / 9$ & $5 / 8 \quad 4^{2.6}$ \\
\hline
\end{tabular}

* The numerator shows the numbers of deaths, and the denominator shows the total numbers in the group.

** Ultracentrifuge-purified JaGAr $¥ 01$ vaccine.

*** Ultracentrifuge-purified Nakayama vaccine.

Table 6. Comparison of Potencies of Ultracentrifuge-Purified Vaccines Prepared from the JaGAr $\# 01$ and Nakayama Strains by the Neutralizing Antibody Test by Plaque Reduction

\begin{tabular}{|c|c|c|c|c|c|c|c|c|c|}
\hline \multirow{4}{*}{ Vaccine } & \multicolumn{9}{|c|}{ Challenge virus } \\
\hline & \multirow{2}{*}{\multicolumn{5}{|c|}{$\frac{\text { JaGAr } \# 01(85 \mathrm{PFU} / \text { plate })}{\text { Vaccine dilution }}$}} & \multicolumn{4}{|c|}{ Nakayama (112 PFU/plate) } \\
\hline & & & & & & \multicolumn{4}{|c|}{ Vaccine dilution } \\
\hline & $4^{1}$ & $4^{2}$ & $4^{3}$ & $4^{4}$ & $\mathrm{ED}_{50}$ & $4^{1}$ & $4^{2}$ & $4^{3}$ & $4^{4} \quad \mathrm{ED}_{50}$ \\
\hline JaGAr $\$ 01$ vaccine ${ }^{* *}$ & $2 / 9 *$ & $5 / 10$ & $6 / 10$ & $9 / 9$ & $4^{2.2}$ & $1 / 10$ & $2 / 9$ & $7 / 10$ & $8 / 9 \quad 4^{2.6}$ \\
\hline Nakayama vaccine*** & $1 / 9$ & $5 / 8$ & $8 / 10$ & $9 / 10$ & $4^{2.0}$ & $0 / 9$ & $1 / 8$ & $4 / 8$ & $4 / 104^{3.6}$ \\
\hline
\end{tabular}

* The numerator shows the numbers of plates showing less than 50 per cent of the number of plaques in the plate of control virus, and the denominator shows the total numbers of plates in the group.

** Ultracentrifuge-purified JaGAr $¥ 01$ vaccine.

*** Ultracentrifuge-purified Nakayama vaccine. 
A preliminary field trial was carried out among the volunteers from newlyemployed technicians of the Kan-onji Institute using this JaGAr $¥ 01$ vaccine. Some individuals in the test group may have recieved Nakayama vaccine before or abortively infected with Japanese encephlitis virus, as judged from the results obtained. Thirty-one persons were inoculated with this vaccine in a dose of 1.0 $\mathrm{ml}$ each on the first, 9th and 30th day. Serum specimens were taken immediately before each inoculation and on the 47 th day after the first immunization. Fig. 8 shows the hemagglution-inhibition antibody responses. The antibody levels increased sharply against the homologous JaGAr $\sharp 01$ strain, and those to the heterologous Nakayama strain also increasaed to some extent.

Fig. 8
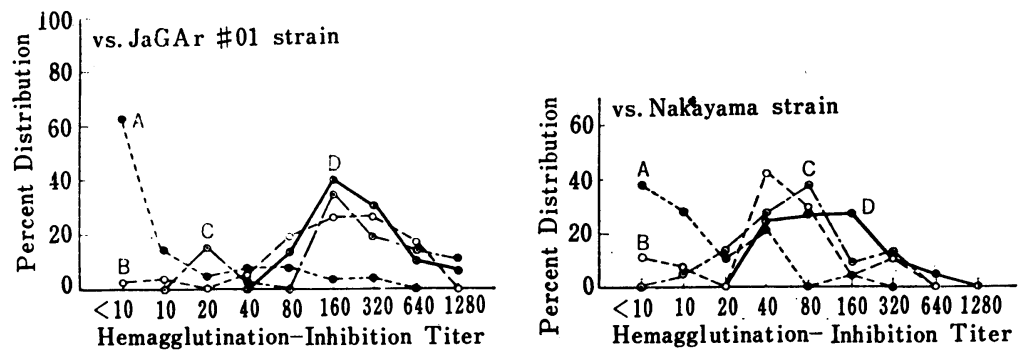

Distribution of Hemagglutination Inhibition Titers against the JaGAr $\$ 01$ and Nakayama Strains of JE Virus before and after Immunization with UltracentrifugePurified JaGAr $\$ 01$ Vaccine. The Vaccine was Inoculated in Doses of $1.0 \mathrm{ml}$ on the 1st, 9th, and 30th Days of the Experiment.

Total number of immunized persons: 31 .

A: Before immunization.

B: 9th day after the first immunization.

C: 21st day after the second immunization (30th day after the first immunization)

D: 17th day after the third immunization (47th day after the first immunization

Many arboviruses have been recognized throughout the world to cause diseases similar to Japanese encephalitis, and most of them are known to multiply in mouse brains in sufficiently high titer to prepare vaccine with high potency. However, fear of possible contamination of the vaccines with the substances causing allergic encephalomyelitis has prevented the practical use of mouse brain vaccine even when these have been recognized to be effective. The method of purification of Japanese encephalitis vaccine described in this paper gives promise for control of a good number of arbovirus diseases throughout the world.

\section{SUMMARY}

Formalin-inactivated vaccine is prepared and purified from brain homogenate from mice infected with Japanese encephalitis virus, strain Nakayama-Yoken. The purification method is based on two cycles of ultracentrifugation of active carbon-treated protamine extract of brain homogenate from moribund mice. This 
gives a very effective vaccine containing very little protein ( 2 to $5 \mu$ g of hot trichloracetic acid-precipitable nitrogen per $\mathrm{ml}$ ). The absence of contaminating substances causing allergic encephalomyelitis was demonstrated by the immunodiffusion technique as well as the animal experiments using the concentrated vaccine.

Purified vaccine is rather labile in phosphate-buffered saline, but can be stabilized with gelatine-added TC Medium 199 buffered with phosphate. The stabilized vaccine was shown to possess its potency over a period of more than 20 months when stored at $4^{\circ} \mathrm{C}$.

Similarly purified vaccine can be prepared from the brains of mice infected with the currently-isolated strain JaGAr $\# 01$.

\section{REFERENCES}

1) Takaku, K., T. Yamashita, T. Osanai, I. Yoshida, M. Kato, H. Goda, M. Takagi and T. Hirota: Japanese encephalitis purified vaccine, Biken Journal 11, 25-39 (1968).

2) Kasahara, S., M. Ueda, Y. Okamoto, I. Yoshida, R. Hamano and R. Yamada: Experimental studies on epidemic encephalitis, Kitasato Arch. Exp. Med. 13, 48-65 (1936).

Kawakita, Y. (ad.): Proceedings of the Committee on Japanese Encephalitis vaccine, Vol. 1 (1966). (in Japanese).

3) Brenner, S. and R. W. Horne: A negative staining method for high resolution electron microscopy of viruses, Biochem. Biophys. Acta 34, 103-110 (1959).

4) Ministry of Health and Welfare (1968): Minimum Requirements of Biologic Products, 1968.

5) Peterson, P. Y.: Experimental allergic encephalomyelitis and autoimmune diseases, Advance Immunol. 5, 131-208 (1966).

6) Kies, M. W.: Chemical studies on an encephalitogenic protein from guinea pig brain, Ann. N. Y. Acad. Sci. 122, 161-170 (1965).

7) Oya, A.: Summary report on the Assay Division of the Committee, in the Proceedings of the Committee on Japanese Encephalitis Vaccine, Vol. 1, 16-17 (1966). (in Japanese).

8) Hale, J. H. and L. D. Lee: A serological investigation of six encephalitis viruses isolated in Malaya, Brit. J. Exp. Pathol. 35, 426-433 (1954).

9) Ogata, T.: Experimental studies on immune response in mice vaccinated with Japanese encephalitis vaccine used in the field (II). Virus 9, 124-129 (1959). (in Japanese, with English summay).

10) Kobayashi, I.: On the immunological differences recognized between two strains of Japanese B encephalitis virus, Virus 9, 475-482 (1959). (in Japanese, with English summary).

11) Matsuyama, T., A. Oya, T. Ogata, I. Kobayashi, T. Nakamura, M. Takahashi and M. Kitaoka: Isolation of arbor viruses from mosquitoes collected at live-stock pens in Gumma prefecture, in 1959, Jap. J. Med. Sci. Biol. 13, 191-198 (1960). 